\title{
Erratum to: Local Polynomial Regressions versus OLS for Generating Location Value Estimates
}

\author{
Jeffrey P. Cohen ${ }^{1}$ • Cletus C. Coughlin ${ }^{2}$ • \\ John M. Clapp ${ }^{1,3}$
}

Published online: 10 March 2017

(C) Springer Science+Business Media New York 2017

\section{Erratum to: J Real Estate Finan Econ DOI 10.1007/s11146-016-9570-3}

There was an important omission in the acknowledgements section of our original article. The corrected acknowledgements section reads as follows:

"The authors appreciate the assistance of Brett Fawley, David Lopez, Diana Cooke, Jonas Crews, and Lowell Ricketts. Participants in the UConn Center for Real Estate 50th Anniversary Symposium and at the NARSC 2014 Annual Meetings provided helpful comments on prior versions of the manuscript. Clapp and Cohen acknowledge support from the Center for Real Estate, University of Connecticut. The views expressed are those of the authors and do not necessarily reflect official positions of the Federal Reserve Bank of St. Louis, the Federal Reserve System, or the Board of Governors. Housing data were licensed from CoreLogic; no views expressed are those of CoreLogic."

The online version of the original article can be found at http://dx.doi.org/10.1007/s11146-016-9570-3

\section{Jeffrey P. Cohen}

jeffrey.cohen@business.uconn.edu

1 Center for Real Estate, School of Business, University of Connecticut, Storrs, CT, USA

2 Federal Reserve Bank of St. Louis, St. Louis, MO, USA

3 Reading University, Reading, UK 